\title{
BIRTH OF DELINQUENTS
}

\begin{abstract}
$\mathrm{A}$ LTHOUGH a connexion between economic depressions and other social catastrophessuch as war-with the origin of delinquency in children has long been suspected, little statistical evidence to support the hypothesis has been available. The evidence is now brought out in a report published by the Home Office Research Unit, entitled Delin. quent Generations*, which shows that the peak of the effect is shown to occur not for those children born during the 1939-45 War, but for those born during 1935-42. These are children a large proportion of whom passed through their fourth to fifth year during the War, suggesting that the social disturbances which occur during the fourth and fifth year of life may have a greater effect than at other ages.

The analysis is based on criminal statistics for the period 1946-57 for each year of birth from 1925-26 to 1948-49. The argument is developed from simpler analyees to a complex process of standardization. In the first place the crime-rate for eightyear-old male offenders is followed from 1946 to 1957, and this shows that the crime-rate was least (for this age) when the number of children of that age was greatest; the statistical work also shows that, for children born after the War, there is a positive correlation between the number of children of a

* Home Office. Delinquent Generations : a Home Office Research Unit Report. (Studies in the Causes of Delinquency and the Treatment of Offenders, No. 3.) By Leslie T. Wilkins. Pp. iv +19. (London: H.M. Stationery Office, 1960.) 18, $6 d$, net.
\end{abstract}

given age at risk and the crime-rate for that age, whereas for pre-War births the tendency is towards a negative correlation.

In 1948, with one of the smallest populations of eight-year-old boys, the crime-rate for this age was the worst for any year of the period studied. There was a continuous and marked improvement until 1956, with 1955 showing the lowest crime-rate (together with the peak of the population bulge). Not only did eight-year-old boys have the worst crime-rate in 1948 but also the highest crime-rate for seventeen-year-old boys occurred in 1957 , when this same generation was seventeen years old.

Analyses of this kind are then generalized for all ages from eight to twenty years of age, for both males and females separately in England and Wales, and for males in Scotland. It is interesting to find that the same patterns of crime-proneness apply to both sexes and to both Scotland and England, notwithstanding that the rates at different ages are not at all similar.

Another finding is that youths between seventeen and twenty-one in 1955 and onwards, who would, according to the general findings of this research, have been expected to be exceptionally delinquent because of the effects of the War, have in fact been even more delinquent than could have been predicted. Either some new and different factor has operated during recent years, or the earlier influences have an additional effect at adolescence.

\section{BILHARZIASIS}

$\mathrm{W}$ HILE economic development usually reduces general morbidity, it has been found in a number of countries that improvement of irrigation networks has resulted in the spread of bilharziasis. Ways of dealing with this growing menace were studied at the second African conference on "Bil harziasis", convened jointly by the World Health Organization and the Commission for Technical Co-operation in Africa South of the Sahara, and held during March 30-April 8, 1960, in Lourenço Marques. The report, which has just been published, constitutes a general assessment of the present bilharziasis control situation in Africa where "the pressing problems of control are related rather to the deployment of skills, materials and work than to the uncertainty of mothods"*.

Assessment of morbidity is complicated by the chronic nature of the disease which may be recognized only if it entails a period of incapacitation for work. Of the three phases of the disease described in the report, the conference considered the last-that of irreversible pathological effects and sequelae-to be by far the most significant from both the public health and the socio-economic point of view. The report directs attention to the pulmonary effects of

- World Health Organization. Technical Report Series No. 204 : Second African Conference on Biharziasis (WHO/CCTA), Lourenco Marques, Mozambique, 30 March-8 April, 1960-Report. Pp. 37. (Geneva: World Health Organization: London: H.M. Stationery Office, 1960.) 1 Swiss franc ; 1s. 9d.; 0.30 dollars.
$S$. haematobium infection, and to the fact that eggs may sometimes be recognized in the sputum of patients. Methods of assessing morbidity are reviewed, and the advantages of certain methods brought out.

The merits of the various types of classic molluscicide (copper sulphate, pentachloriphenate) and also of the more recent products (Bayer 73, I.C.I. 24223, and 'Aqualin') are examined, together with ways in which these products are used in African territories. Water management, land use and agricultural practices were examined at length in relation to the transmission and spread of bilharziasis. Some countries in the African region have adopted legislation relating to the control of communicable diseases, and the report cites an example of one law which might be modified and adapted to locel health and economic conditions elsewhere. Methods of irrigation and agriculture and of bilharziasis control aspects of engineering techniques applied to watercourses, ponds and reservoirs are studied, and the frequently neglected possibility of using rainwater is also touched on.

In addition to the steps taken to improve irrigation plans, it would be desirable to construct bridges and culverts, to install safe washing and bathing places and at the same time to develop an effective health education programme so that people may be made aware of the danger of natural waters. 